\title{
Formação para o Moderno Serviço Público
}

\author{
David Mars
}

E

M artigo publicado no último número desta Revista, tratamos de certas modificações ocorridas na maneira pela qual hoje se encära Administração Pública, em confronto com aquela por que era considerada há poucas décadas atrás. A questão então suscitada foi a seguinte: que significação terá essa mudança para o moderno administrador?

A resposta, que aqui resumiremos de modo muito sucinto, tocalizou a atenção para os seguintes pontos:

$\left.1^{\circ}\right)$ necessidades de conhecer e compreender as técnicas básicas de administração;

$\left.2^{\circ}\right)$ conhecimento da dinâmica e da organização da comunidade em que vive o administrador;

39) esfôrço constante no sentido do aperfeiçoamento do processo de comunicação dentro da organização;

4\%) estabelecimento de um clima capaz de incentivar a eficiência e a produtividade de pequenos grupos dentro da organização;

5\%) estabelecimento de um clima de criatividade;

6\%) realização das necessárias atividades de aperfeiçoamento, inclusive treinamento $e$ instrução, para administradores de todos os niveis.

Finalmente, suscitamos a questão: quais as implicações da mudança, na formação do moderno administrador? Mencionamos três fatôres: redução do número de cursos técnicos e ênfase nos cursos que abranjam novos métodos, bem como na pesquisa. O exame aprofundado dêsses três fatôres constitui a essência do presente artigo.

O primeiro ponto não exige muita discussão. $O$ que devemos tornar claro é que os cursos de técnica de administração não são, por si, maus. O provável é que quanto mais um futuro administrador aprender sôbre as técnicas de administração de pcssoal, administração financeira, organização e métodos e assuntos correlatos, mais eficiente poderá ser na prática. Se um estu- 
dante de administração dispusesse de tempo ilimitado para preparar-se, poderia fazer um numero ilimitado dêsses cursos e cada um dêles contribuiria para seu aperfeiçoamento, embora, provàvelmente, em bem pequena dose.

O problema, todavia, é que o tempo do estudante não é ilimitado. Sua própria situação - e a sociedade - exige que prossiga em sua carreira como estudante, termine o curso e comece a atuar produtivamente no mundo real. Com o tempo li mitado, a formação do estudante deve basear -se num equilibrio entre cursos técnicos e outros tipos de processos educacionais.

Mas, que tipos de processos? Chegamos, neste ponto, ao segundo fator. Para que o moderno administrador fique apto a realizar aquilo a que nos referimos no comêço dêste trabalho, terá que enfrentar assuntos e matérias de que ninguém cogitava durante o período "clássico" da Administração - a época de Taylor e Fayol. Necessitará de cursos, geralmente de Ciências Sociais, particularmente de Ciência Politica, Psicologia e Sociologia. Se possivel, deverá fazer cursos de matérias tais como comunicação, chefia, processo decisório e outros assuntos correlatos.

Sem sugerirmos qualquer paralelo ou analogia direta quanto ao Brasil, convirá por um momento lançar um olhar no preparo para o serviço público num país onde tal preparo já se desenvolveu em alto grau — os Estados Unidos da América. Uma das mais conhecidas escolas de Administração Pública nos Es tados Unidos - a da Universidade do Sul da Califórnia exige atualmente do estudante, para a obtenção do diploma de bacharel, 32 cursos ou quatro por semestre durante oito semestres (quatro anos). Dêstes, 26 são obrigatórios e seis facultativos, mas, mesmo entre os obrigatórios, há grande variedade de escolha, conforme veremos.

Sendo o currículo da Escola de Administração Pública da Universidade do Sul da Califórnia muito nôvo e ligado a uma ampla reorganização, ( ${ }^{\star}$ ) convirá talvez examiná-lo aqui em linhas gerais. São os seguintes os 26 cursos obrigatórios:

19) Composição inglêsa.

29) Lógica (Filosofia).

3. $5^{\circ}$ ) Três cursos consecutivos de linguas estrangeiras, ou introdução à Matemática Lógica Simbólica (Filosofia) e Estatís-

$\left(^{*}\right)$ Convém notar que, em vista da completa reorganização dos currículos e cursos, recentemente realizada, cada curso agora conta por quatro unidades de crédito ao invés de três. Significa isso que os estudantes fazem menor número de cursos na universidade, mas têm mais tempo pa"a dedicar-se preferência ao extensivo. 
tica na Administração Pública (ou equivalente, mediante requerimento).

6?) Um curso escolh:do entre nove cursos básicos de Astronomia, Biologia, Quimica, Geologia, Física.

7) Um curso escolhido em seis cursos básicos de História.

8) Um curso escolhido entre três cursos básicos de História dos Estados Unidos ou Govêrno Americano (Ciência Politica).

9?) Um curso escolhido entre treze cursos básicos de Filosofia ou Religião.

10) Um curso escolhido entre sete cursos básicos de Antropologia, Economia, Geografia, Relações Internacionais, Ciência Politica, Psicologia, Sociologia.

11\%) Ulm curso escolhido entre sete cursos de Inglês, Jornalismo e Oratória.

12.) Um curso escolhido entre treze cursos de Teatro, Belas Artes, História da Música e Literatura, Dança (educação física).

13) Um curso escolhido entre quinze de Estudos Americanos Cláss'cos, Literatura Comparada, Inglês, Francês (literatura), Alemão (literatura), estudos eslavos, espanhol (literatura), Oratória.

14\%) Um curso escolhido entre seis de História dos Estados Unidos.

Neste ponto, o preparo básico do estudante, correspondente mais ou menos aos dois primeiros anos, pode ser considerado completo e êle estará apto a iniciar o estudo mais especializado de administração e matérias correlatas.

15\%) Administração e recursos financeiros.

16\%) Administração de recursos de pessoal.

17\%) Análise do Sistema Administrativo.

18\%) Chefia e Comportamento Administrativo.

198) Filosofia e Administração Pública.

20\%) Um dos seguintes cursos de Administração Pública: Instituições Governamentais Administrativas, Estaduais e Nacionais, Govêrno e Administração de Áreas Metropolitanas.

21. 22\%) Dois dos seguintes cursos de Administração Pública: Direito Administrativo; Administração Comparada; Política e Administração; Problemas de Adminstração Pública; A Comunidade e o Processo de Administrar.

23) Um dos seguintes cursos de Ciência Política: Poder Politico; Grupos de Interêsse; Opinião Pública e Propaganda; 
Processo Legislativo; Partidos Politicos Norte-Americanos e Politica Prática; Pensamento Politico Norte-Americano.

24) Um dos seguintes cursos de Economia: Tributação, Finanças Públicas e Política Fiscal; Principios de Política Internacional; Problemas e Diretrizes; Economia de Terras Urbanas; Filosofia e Planejamento Econômico Comparados; Politica Econômica do Govêrno e da Emprêsa Privada.

25:) Um curso escolhido entre os cinco seguintes, sendo os três primeiros de Sociologia, o quarto de Psicologia e o último de Antropologia; Psicologia Social; Sociologia Urbana e Rural; A Comunidade Norte-Americana; Principios de Psicologia Social; Antropologia Social da América Contemporânea.

26:) Um curso escolhido entre os cinco seguintes (o primeiro de Ciência Política, o segundo de Psicologia, o terceiro de Antropologia e o último de Filosofia): Análise do Comportamento Politico: técnicas de Mensuração e Levantamento; Pesquisa de Opinião. Levantamentos e Pesquisa de Motivação; Métodos de Campo em Antropologia Cultural; Estudo da História e Filosofia da Ciência; Teoria dos Conhecimentos.

Os cursos 27-32 são optativos, escolhidos livremente pelo estudante, com o auxílio de seu orientador, quer dentro de seu setor de estudo, quer de outros departamentos e escolas da própria Universidade. Essa liberdade de escolha possibilita ao estudante aprofundar seus conhecimentos no campo de seu inte. rêsse ou experimentar outras matérias.

Embora o currículo possa parecer refletir muito de perto a clássica predileção norte-americana por uma educação baseada na cultura geral para a maioria dos estudantes universitários (inclusive futuros administradores), é claro que reflete também certa preocupação pelo tema de nossa discussão. Em certos cursos tais como os de Poder Politico, Interêsses de Grupos, Opinião Pública e Propaganda; Chefia e Comportamento Administrativo; Filosofia, Administração Pública e outros, o futuro administrador é levado a refletir a fundo acêrca do processo de administração e sua relação com outros fenômenos sociais e é pôsto em face de questões nunca suscitadas em cursos tècnicamente orientados.

O produto dêsse currículo será, muito promissoramente, c tipo de pessoa que depois de acrescentar ao preparo acadêmico alguns anos de experiência prática, torna-se o tipo de administrador capaz de realizar aquilo que descrevemos no comêço dêste trabalho.

Ao lado de novos cursos tais como de Chefia Comunicação, etc., foram também introduzidas novas técnicas que podem ser usadas para animar e motivar o estudante de administração 
e tornar mais proveitosos seus anos de estudo. Nesta altura convém frisar um ponto importante. Até aqui, pelo que dissemos, poder-se-á pensar que existe uma completa separação entre os cursos técnicos e os de orientação mais moderna. Êsse não é, absolutamente, o caso, pois é possivel tratar dos assuntos mais tradicionais de um modo francamente não tradicional, dando-se nova visão da matéria e despertando maior interêsse no estudante. $O$ fato de tratar por essa forma as matérias tradicionais também torna possivel conservar os antigos tipos de curso de administração, quando conveniente. Em outras palavras, o nome do curso pode ser conservado mas o método de ensinar a matéria será muito diferente.

Durante as últimas décadas, desenvolveram-se inúmeras técnicas pedagógicas, muitas das quais apropriadas ao ensino da administração. Essas técnicas, em sua maioria dependem grandemente da participação do estudante, resultando daí uma sensivel redução das aulas e da prepotência do professor. Discutiremos a seguir três dessas técnicas: dramatização, exercícios e casos. Convém frisar, porém, que estamos dando apenas alguns exemplos das muitas maneiras pelas quais um professor dotado de imaginação pode dar realidade a uma aula de administração, baseado no principio de que a melhor maneira de ensinar essa matéria (aliás, também quase tôdas as outras) é sua demonstração prática. Outros métodos incluem visitas a repartições, visitas de administradores, demonstrações audio-visuais, projetos de trabalho, exame de documentos oficiais, exercicios de prática de administração, etc.

A dramatização é uma espécie de representação destinada a dar ao aluno a sensação dos processos mentais e emocionais que o administrador experimenta em seu trabalho, tipicamente a tomada de uma decisão. Cada um dos participantes da dramatizacão é devidamente informado acêrca do personagem que irá representar, do cargo que ocupa e das circunstâncias que levam à ocorrência a ser dramatizada. Há inúmeras maneiras de aproveitar-se êsse método. As informações podem ser dadas por escrito ou não, podem ser vagas ou minuciosas, dependendo do que o professor pretende fazer com o exercício. Da mesma forma, a dramatização pode ser feita apenas entre duas pessoas ou num grupo (isto é, representação de vários papéis).

Todos os alunos poderão participar do exercício ou apenas um pequeno número (voluntários ou escolhidos), enquanto os demais figuram como observadores. Depois de cada dramatização o professor geralmente procura colhêr as impressões dos participantes: que importância atribuem à experiência na maneira pela qual encaram a administração, o que viram acontecer nos 
casos em que participaram apenas alguns alunos e assim por diante.

Resumindo, vejamos algumas das maneiras de aplicar o método de dramatização:

a) tôda a classe participará, cada aluno voltado para o vizinho, encenando uma simples situação. Pode ser, por exemplo. uma entrevista com um candidato a emprêgo, um dos estudantes representando o candidato e o outro, o entrevistador;

b) o mesmo que a), com a diferença que, ao cabo de certo tempo, o professor interrompe a dramatização e pede aos participantes que invertam os papéis;

c) depois de a) e b), ou em seu lugar, um par ou uma série de pares de estudantes executa a dramatização perante tôda classe, seguindo-se as críticas feitas pelos assistentes sôbre o que viram e

d) a mesma série de alternativas, a), b) e c), pode ser usada para exercícios de representações múltiplas.

Os exercícios de simulação também visam a transmitir ao estudante de administração a realidade e 0 sabor do trabalho de administração. Um dos exercicios típicos de simulação é chamadio exercício da caixa de entrada. Neste caso, os estudantes - e geralmente tôda a classe participa do exercicio - recebem informações básicas acêrca da organização na qual se localizou a simulação. Recebem o que representa o conteúdo da caixa de entrada de um administrador, constituído principalmente de corres pondência de várias espécies: cartas, memorandos internos, notas de telefonemas. Finalmente, são informados do prazo em que deverão despachar todos os ássuntos da correspondência que têm à sua frente: assinar as cartas prontas ou fazer as necessárias modificações, preparar as respostas necessárias para os memorandos, indicar as decisões a serem tomadas nos casos em que seja necessário tomá-las, e assim por diante.

Finalmente, há o método do caso. Muitos tipos de casos existem em administração pública, mas em seu conteúdo pedagógico têm todos um objetivo comum: levar ao estudante uma dimensão de realidade em seu estudo do processo de administrar mediante o exame de algum ato administrativo em maior ou menor minúcia. Como tal, o método do caso assemelha-se aos exercícios de dramatização e de simulação, acrescentando-lhes uma pode. rosa arma em que o moderno professor de administração pode apoiar-se confiantemente.

O ensino da administração pública ficou muito atrás do das demais disciplinas, principalmente da administração de emprêsas 
e de Direito no preparo e na utilização pedagógica de casos. Os noventa casos de administração pública do Programa Interuniversitário de Casos nos Estados Unidos constitui uma pequeníssima fração dos muitos milhares já elaborados em administração de emprêsas e dos milhões de casos em Direito norte-americano.

Os casos podem ser uma arma de dois gumes. Casos prèviamente preparados são usados para ensinar e ilustrar vários aspectos do processo de administração. Como tal, deve ser cuidadosamente integrados na estrutura básica do curso, para que os estudantes possam beneficiar-se ao máximo com seu estudo. Além disso, porém, os estudantes são levados e incentivados a elaborar êles próprios alguns casos. Êsse exercício leva-os ainda mais perto da realidade administrativa e ao mesmo tempo pode concorrer para aumentar o número de casos a serem usados no futuro. Evidentemente a incumbência de escrever casos pode ter enorme êxito numa classe em que alguns estudantes já tinham tido experiência administrativa.

Um dos mais interessantes tipos de método do caso é o chamado processo do incidente, criado pelo Professor Paul Pigors do Instituto de Tecnologia de Massachusetts (às vêzes também chamado Método Pigors em honra de seu criador). No processo do incidente, conforme o nome sugere, os estudantes recebem ligeiras informações sôbre algum incidente administrativo ocorrido. Trabalhando junto com os estudantes, há uma "pessoa-recurso" que pode ser o professor ou outro elemento. A "pessoa-recurso" colhe antecipadamente tôdas as informações sôbre o incidente e seus antecedentes. Cabe, então, aos estudantes conseguir informações tão completas quanto possivel, formulando perguntas àquela pessoa. Geralmente dispõem de um período de tempo fixado, durante o qual podem formular as perguntas, o que proporciona o aquilatamento da qualidade das mesmas, do ponto de vista da inteligência, pesquisa e importância. Uma vez obtidas as informações necessárias, o grupo passa à decisão. Esse processo proporciona excelente treinamento para o futuro administrador, por reproduzir exatamente o que pode ocorrer em sua carreira. Será êle notificado de que algo ocorreu em alqum ponto de sua organização e de que deve tomar uma decisão a respeito. A não ser que esteja situado em pôsto suficientemente alto na hierarquia administrativa para dispor de assessôres capazes de dar-lhe as necessárias informações, terá que encontrar sòzinho essas informações, o que fará muito melhor se formular perguntas adequadas. (Mesmo que disponha de assessôres, precisará ser capaz de formular aos mesmos perguntas adequadas para não ficar merguThado em informações irrelevantes). 
Resta agora discutir um tipo final de caso: o caso orientado pela pesquisa, às vêzes denominado histórico do caso ou estudo do caso. A discussão sôbre êsse tipo de caso também nos leva ao terceiro tópico da discussão: a importância da pesquisa no plano preparação do moderno administrador público.

O histórico do caso representa trabalho mais longo do que qualquer outro tipo de caso. De fato, pode constituir até mesmo um livro. Nesse tipo de caso, tenta-se tomar um ato administrativo (ou legislativo, executivo ou politico) e examinar em minúcias os fatôres que deram lugar ao mesmo, os pontos de vista dos partıcipantes e a ação por êstes adotada. E' fácil compreender que êsse método exige muita pesquisa para seu preparo e para que possa preencher sua finalidade básica de exposição (Também exige muita capacidade de redação, para torná-lo de leitura interessante).

E mais: é preciso cuidado para não tomar literalmente as diferenças de denominação, feitas mais ou menos arbitràriamente. O histórico do caso, a par de constituir para seu autor um documento importante de pesquisa, representa também importante instrumento de ensino. Um caso dêsse tipo, se bem elaborado, pode fornecer aos estudantes de administração uma sensação real de natureza multidimensional do mundo administrativo, o que de fato é o tipo de opinião que mais se aproxima da realidade. Um dos defeitos dos tipos mais resumidos de casos é que freqüentemente encobrem a complexidade de processo de administração e, a menos que o professor tenha o cuidado de esclarecer bem êsse ponto, os estudantes podem vir a assumir uma idéia por demais simplificada do que é, na realidade, a administração.

No tocante à pesquisa de um modo geral, é claro que a complexidade que se tornou a marca das modernas organizações criou a necessidade crescente de informações para os administradores. E claro, igualmente, que a pesquisa é a chave de tais in-
formaçôes.

Uma coisa assustadora que muitas vêzes ocorre para preocupar professôres, estudantes e técnicos de administração é a verificação de que, a despeito de tôdas as pesquisas realizadas. nesse setor nos últimos anos, não conhecemos ainda muito acêrca rificamos que os principios, aforismos e leis de administração ensinadas nas classes durante os anos clássicos da disciplina, pouca ou nenhuma relevância têm na vida real das organizações. Se, porém, por exemplo, a solução para os problemas que surgem num sistema democrático é mais democracia, a solução para os: 
problemas que surgem por falta de informação sôbre um assunto será mais informações, isto é, mais pesquisas.

Os estudantes de administração devem aprender a importância da pesquisa desde o início de seu curso. Mas não se ensina pesquisa teòricamente. Nesta, como em outras áreas, a experiência é a melhor mestra; por isso os estudantes devem ser levados a realizar projetos de pesquisa por conta própria. Alguns aprenderão a fazer boas pesquisas e poucos talvez até virão a tornar-se bons pesquisadores. Mas se nada mais apren derem, aprenderão que fazer uma boa pesquisa é coisa difícil e, no futuro, poderão apreciar melhor os esforços dos pesquisadores ligados às suas organizações.

Neste ponto, também, há o risco de aceitar os rótulos muito literalmente. Pode parecer que ensino e pesquisa sejam duas atividades distintamente diferentes. Na realidade, porém, não 0 sã). Devem ser consideradas como os dois lados da mesma moeda. O ensino deve fornecer a base filosófica para a administração e suscita questões básicas, ao passo que a pesquisa deve procurar fornecer a informação com as quais essas perguntas possam começar a ser respondidas. Já se disse, a respeito de uma outra divisão arbitrária, entre as disciplinas de Ciências Sociais, de que a Política sem a História não tem raizes, embora a História sem a Política não tenha frutos. O mesmo se pode dizer do ensino e da pesquisa.

Outro ponto que deve ser esclarecido quanto ao ensino e à pesquisa é exatamente o mesmo que citamos antes no tocante à relação entre os curșos clássicos e modernos de administração. Embora todo programa de ensino de administração pública deva incluir um ou mais cursos de metodologia, técnica e prática de pesquisa, a pesquisa não deve, de modo algum, ser confinada a êsses cursos. Tendo aprendido a técnica da pesquisa e isso mostra que os cursos de pesquisa devem ser oferecidos ao estudante no comêço do programa - o estudante deve então ter oportunidade e incentivo para aplicá-la em muitos dos outros cursos. Tal aplicação o ajudará a fazer viverem êsses cursos e, ao mesmo tempo, o levará mais perto da realidade administrativa.

As sugestões feitas acima, se implementadas inteligentemente, servirão a dois objetivos, ambos fundamentais no mundo moderno: uma experiência mais interessante e desafiadora para o estudante de administração e um preparo que o equipara melhor para as pressões e exigências complexas e multiformes do mundo administrativo. 